\title{
The Missing Committees: Research Ethics in the Making in Switzerland
}

\author{
Magaly Tornay \\ Institute for the History of Medicine, University of Bern, Bühlstrasse 26, \\ 3012 Bern, Switzerland \\ magaly.tornay@img.unibe.ch
}

\begin{abstract}
This article analyzes the formation of research ethics and particularly of ethics committees in Switzerland by tracing their early history along distinct phases: (1) the first guidelines on human experimentation issued by the Swiss Academy of Medical Sciences in 1970; (2) conceptual struggles in establishing these norms; (3) the emergence of a central medical-ethical committee in 1979; and (4) the first local ethics committee established in the rural canton of Thurgau in 1987. It analyzes the interplay between local practices, industrial standards, and a neoliberal, low-key, soft regulation by negotiation among peers. Key actors are the Swiss Academy of Medical Sciences, the pharmaceutical industry, and the canton of Thurgau. In this context, 'research' and 'experiments' for a long time remained disputed, unclear and risky notions. REC s were encouraged mainly as a way of distributing responsibility, of managing a wide array of risks and, crucially, as part of a wider strategy to avoid juridical and political regulation. The article asks, on a more general level, how and why 'ethics' entered this field and what becomes visible or obscured when issues are transposed into an ethical language.
\end{abstract}

\section{Keywords}

ethics committees - research ethics - legitimation by procedure - clinical trials

The history of biomedical ethics has often been portrayed as a teleological development. In this view, advances in modern medicine and biotechnology 
have created problems that required not only answers but a new mode of responding, which was eventually found in the format of procedural ethics. ${ }^{1}$ Some issues, however, have a longer history and have moved in and out of the ethical realm several times. ${ }^{2}$ The shift under the umbrella of ethics was also linked to social processes, and although ethics often uses universalistic language, this language is itself subject to historical change. ${ }^{3}$ In a similar vein, Niklas Luhmann has described the relationship between technology and ethics as more complex than the one between "dirt and soap". He argued that they evolved independently, touching each other only by chance. ${ }^{4}$ Luhmann's radical doubt helps to untangle ethics from being merely a problem-solving device and to instead consider "ethicization" 5 as something in need of historical examination. Research on humans, for example, has become ambivalent at least since the Nuremberg trials in the aftermath of World War II, but it took until the 196 os for it to be regulated through ethical norms. ${ }^{6}$

This article analyzes the contingencies of research ethics in Switzerland using sources from the Swiss Academy of Medical Sciences (SAMs), the main body issuing ethical guidelines in the country. Even though they were discussed

1 See, e.g., Andreas-Holger Maehle and Johanna Geyer-Kordesch, eds., Historical and Philosophical Perspectives on Biomedical Ethics: From Paternalism to Autonomy? Ashgate Studies in Applied Ethics, (Aldershot, 2002) 1. For the complex relation between technology and ethics, see Petra Gehring, "Fragliche Expertise: Zur Etablierung von Bioethik in Deutschland," in Wissenschaft und Demokratie, ed. Michael Hagner (Berlin, 2012): 112-139, 137.

2 For example, in reproductive medicine; see Caroline Arni, "The Prenatal: Contingencies of Procreation and Transmission in the Nineteenth Century," in Heredity Explored: Between Public Domain and Experimental Science, 1850-1930, eds. Christina Brandt and Staffan Müller-Wille (Cambridge, MA-London, 2016), 285-309.

3 For this argument, see our larger project on historicizing biomedical ethics at www.img.unibe. ch/forschung/medizin_und_bioethik_in_der_schweiz/index_ger.html, accessed 30 August 2021.

4 Niklas Luhmann, “Technik und Ethik' aus soziologischer Sicht," 2. Akademie-Forum Technik und Ethik, Vorträge der Rheinisch-Westfälischen Akademie der Wissenschaften (Cologne, 1987): 31-34, 31 [my own translation]; see also Gehring, "Fragliche Expertise," 112.

5 See Alexander Bogner, "Ethisierung oder Moralisierung? Technikkontroversen als Wertkonflikte," in Ethisierung der Technik - Technisierung der Ethik. Der Ethik-Boom im Lichte der Wissenschafts- und Technikforschung, ed. Alexander Bogner (Baden-Baden, 2013), 51-64.

6 See, e.g., Volker Roelcke, "Historical perspectives on human subjects research during the 2oth century, and some implications for present day issues in bioethics," in Twentieth Century Ethics of Human Subject Research: Historical Perspectives on Values, Practices, and Regulations, ed. Volker Roelcke and Giovanni Maio (Stuttgart, 2004), 11-18; Paul Weindling, "The Origins of Informed Consent: The International Scientific Commission on Medical War Crimes, and the Nuremberg Code," Bulletin of the History of Medicine, 75 (2001), 37-71. 
quite early, REC s and ethics committees based on the idea of "group consideration"7 were installed only gradually. Their emergence was a fluctuating process characterized by conflicts of interest between science and politics, centralizing and decentralizing dynamics, and a struggle for conceptual clarification; crucial terms such as risk, experiment and trial were ambiguous and seemed to undermine the traditional doctor-patient relationship. Once consensus was found on wording, and once guidelines were issued, a gap opened up between paperwork and practice, resulting in an absence of RECs in Switzerland over the course of the 1970s.

The paper analyzes three distinct phases in the formation of research ethics in Switzerland: (1) the first guideline on human experimentation issued by the Swiss Academy of Medical Sciences in 1970; (2) conceptual struggles in establishing these norms; (3) the emergence of a central medical-ethical committee in 1979; and (4) the first local ethics committee established in the rural canton of Thurgau in 1987.

The overall aim was to avoid legal and political oversight, making tangible a liberal mode of governance that took the form of low-threshold negotiation among insiders. ${ }^{8}$ Insiders in this case included the pharmaceutical industry from early on, in line with the country's policy of facilitating high-tech and research hubs. The motif of inside and outside, both in terms of who sets norms and where risks are located, runs as a thread through this story. By focusing on the prehistory of RECS in Switzerland, negotiations, conflicts and intricacies become tangible in action, before the metaphorical black box was closed and REC s were running. 9

In what follows, I argue that ethics does not primarily solve problems, but articulates them in a new language and shifts them into another discourse. It thus makes some things visible and obscures others, producing a whole new mix of difficulties and possibilities. ${ }^{10}$ The concept of "agnotology", coined by Londa Schiebinger and Robert Proctor, is helpful to explore these shifting visibilities. It describes the deliberate creation of doubt as a political strategy, for

7 On inventing group consideration, see Laura Stark, Behind Closed Doors: IRBs and the Making of Ethical Research (Chicago, IL, 2012), 106-108.

8 See also Adam Hedgecoe, "A Form of Practical Machinery': The Origins of Research Ethics Committees in the UK, 1967-1972," Medical History, 53 (2009), 331-350; Stark, Behind Closed Doors.

9 On opening the black box, see Bruno Latour, Science in Action: How to Follow Scientists and Engineers Through Society (Cambridge, MA, 1987), 2f.

10 On ethics as a problem shift, see Luhmann, "Technik und Ethik," 33. 
example in climate science or the tobacco industry. ${ }^{11}$ Biomedical ethics serves to generate the opposite of doubt - trust. ${ }^{12}$ But both trust and doubt rely on mechanisms to reduce social complexity. In this perspective, ethics is not primarily about producing knowledge, but about negotiating expertise and creating acceptance in the realm of biopolitics.

\section{Ethics Enters the Academy: Establishing a First Guideline}

The Swiss Academy of Medical Sciences was established in 1943 as a private foundation initially to promote medical research. Its founding members were the faculties of medicine and veterinary medicine, as well as the Association of Swiss Physicians; the lion's share of its assets came from donations from the pharmaceutical companies in Basel, which also manned many senior Academy positions throughout its history. ${ }^{13}$ More than twenty years later, the Academy became active in the field of ethics. In 1969, it issued its first guideline on the "definition and diagnosis of death"; to date, a total of 28 guidelines have been published, some of which have been incorporated into legislation. Although the guidelines are primarily aimed at the medical profession, the Academy's relations with politics, legislation and the media grew closer over the years, making it one of the main players in biomedical ethics in Switzerland. ${ }^{14}$

This turn towards ethics was, to some extent, related to the issues of research on humans. As Petra Gehring points out, human experimentation was generally the dominant issue paving the way for biomedical ethics. ${ }^{15}$ The

11 Robert Proctor and Londa Schiebinger, eds., Agnotology: The Making and Unmaking of Ignorance (Stanford, CA, 2008).

12 On the production of trust, see Adam Hedgecoe, Trust in the System: Research Ethics Committees and the Regulation of Biomedical Research (Manchester, 2020).

13 See Schweizerische Akademie der Medizinischen Wissenschaften, ed., 5o Jahre Jubiläum (Basel, 1993). In 1976 it was stated internally that the Academy was financed "to about 90\%" by the industry: IMG, SAMS-Archive, B o1-8, minutes of board meeting, 18 March 1976, 9 .

14 Since the late 1970s, the SAMS increasingly became involved in parliamentary consultation processes and was also directly asked by lawmakers to provide opinions; see, e.g., G 12-6, memo of the meeting on 11 January 1979 with Prof. Hausheer, Vice-director of the Federal Office for Justice, 3 f.

15 Later, the topics of contraception, abortion and transplantation joined in, giving rise to "bioethics" in the U.S.; see Petra Gehring, "Ethik und Politik, Ethik als Politik, Ethikpolitik," in Wozu Ethik? ed. Gerhard Gamm and Andreas Hetzel (Bielefeld, 2015): 19-39, 30. Lettow sketches similar thematic conjunctures in the field, pointing to human research, abortion and the doctor-patient relationship as core topics of the 1960s and 7os; see Susanne Lettow, Biophilosophien. Wissenschaft, Technologie und Geschlecht im philosophischen Diskurs der Gegenwart (Frankfurt-New York, 2011), 35. 
Academy initially viewed this as something that could be resolved quickly, in a few sessions that would result in a small set of general, low-threshold behavioral guidelines for physicians. It turned out, however, that ethics would not go away. On the contrary, the issue of human experimentation became a gateway for biomedical ethics in general into the realm of the Academy, causing it to change its organizational form entirely. ${ }^{16}$

While the first set of guidelines responded to practical and legal problems arising from individual transplantation cases in hospitals, the second set of guidelines on "Research Investigations in Humans" (1970) opened the door towards experimental science. The questions around human experimentation expanded beyond bedside practices and the individual patient-doctor relationship, requiring a whole new weighing of interests between science, the individual patient, and general healthcare. ${ }^{17}$

The first impetus for setting norms in this area came from the international medical community: in 1969, five years after the Declaration of Helsinki was issued, several Academy members attended a conference at Chateau Bossey overlooking Lake Geneva to discuss possible modifications and expansions of the Declaration. ${ }^{18}$ It was in subsequent to this conference that the Academy began to debate research ethics, installing a commission to develop a guideline on the "problems surrounding human research" with 20 male members, including two representatives from the pharmaceutical firms Geigy and Sandoz, a professor of forensic medicine, internists, surgeons, pediatricians, pharmacologists, and psychiatrists. "It is emphasized that these problems are to be discussed in a small circle of interested parties - to the exclusion of lawyers and theologians", the minutes of the board meeting note, without providing further explanation..$^{19}$ In order to address the issue of reduced power of consent and judgment in children and psychiatric patients, pediatricians and psychiatrists were invited to join the human research group. ${ }^{20}$ The involvement of moral theologians had already been discussed for the previous guideline on the

16 In contrast to other countries, it was not the training of individual medics, which the sams addressed only later. On the changing shape, see section 3 of this paper.

17 See Gehring, "Ethik und Politik," 30.

18 On the Declaration of Helsinki, see Susan Lederer, "Research Without Borders: The Origins of the Declaration of Helsinki," in Roelcke and Maio, Twentieth Century Ethics of Human Subject Research, 199-217.

19 B o1-6, minutes of board meeting, 21 February 1969, 14.

20 See Jonas Born, "Kodifizierung von Ethik in der Schweiz. Die Genese der 'Richtlinien für Forschungsuntersuchungen am Menschen' durch die 'Schweizerische Akademie der Medizinischen Wissenschaften', 1969-1970" (bachelor thesis, Institute for the History of Medicine, University of Bern, 2017). 
definition and diagnosis of death, leading to "vivid debates" and to the statement that, "we want to remain among ourselves for the time being [...] and not leave the agenda in other hands". ${ }^{21}$ Ethical issues were to be resolved primarily among physicians and pharmacologists, excluding actors representing wider social interests or ethics in a moral-philosophical, non-applied sense, but including, in the end, lawyers to discuss legal implications. ${ }^{22}$

The commission produced a code of conduct for research on humans based on the Declaration of Helsinki in six meetings in just over a year. It was important to the Academy not "to draw up any legal provisions" and to only prepare "recommendations", while at the same time it sought to actively occupy the field, so that legal regulation could be avoided. ${ }^{23}$

There was a certain urgency in this matter. Participants in the preparatory sessions pointed to the U.S., where hospitals had already established Institutional Review Boards and where "bureaucracy" in legislature seemed to "hinder" free research. ${ }^{24}$ "If we do nothing", warned one discussant, "a control body may be created by the legislature instead". ${ }^{25}$ The risk, it was noted, was not borne by an individual clinic director in the U.S. but by a group. This idea of shared responsibility would also be of "great value to the industry" in Switzerland, as was stated. ${ }^{26}$ The form under discussion remained vague: such bodies should consist of "smart people" and have an advisory, not overly controlling role; possibly at the level of individual hospitals, universities, or under the aegis of the Academy. ${ }^{27}$ What should be avoided at all costs, according to a representative of the pharmaceutical industry, was "legal control by a commission" that might even want to "inspect trial protocols and demand a say". 28

The commission then debated whether such a body should "control", "advise", or merely "review", since mandated control might diminish the responsibility of the individual physician. Finally, the phrase 'any planned investigation should be submitted to a panel' was deleted in favor of the mere option of submitting a trial plan. ${ }^{29}$ The level was intentionally left open: "it

\footnotetext{
21 B o1-6, minutes of board meeting, 10 February 1968, 10 [all quotes translated by the author].

22 Six lawyers were invited to the last two meetings to give legal advice.

23 H o6-10, minutes of 1st commission meeting, 17 May 1969, 7.

24 Ibid., minutes of 2nd commission meeting, 27 September 1969, 4, 6. On IRBs, see Stark, Behind Closed Doors.

25 H o6-10, minutes of 2nd commission meeting, 27 September 1969, 5 .

26 Ibid.

27 Ibid., 6, 11f.

28 Ibid., 11 .

29 Ibid., minutes of 3rd commission meeting, 13 December 1969, 8.
} 
may be internal in a clinic or ward, or faculty"; a national infrastructure did not seem desirable. ${ }^{30}$

The idea of group consideration had thus already taken hold within the group. ${ }^{31}$ The members were familiar with the model not only from the American example, but also from similar expert panels for radiation protection in Switzerland, to which they frequently referred. ${ }^{32}$ After all, such expert committees were not new in form, as they had also been set up in Germany, for example, for the regulation of hazardous substances. ${ }^{33}$

Still, the risks and dangers that such panels and guidelines were meant to tackle were not clear-cut. Luhmann introduced a fundamental distinction between the two: while risk describes future damage internal to a system that can be attributed to a decision, danger is always external, belonging to the environment, like rain (danger) versus the decision to leave the umbrella at home (risk). ${ }^{34}$ In the preparatory meetings for the guideline on human trials, it remained unclear where the dangers or risks were to be located: were they intrinsic to medicine, or external, for example, in society? This question also related to that of whom to include on such panels: internal voices from the medical community or more diverse external voices? Even though the form of expert committees in the sense of professional self-limitation was already familiar, e.g., from dealing with hazardous substances, something had changed by the end of the 196os. Ulrich Beck had called it the emergence of the risk

$30 \quad$ Ibid., 9 .

31 On group consideration, see Stark, Behind Closed Doors, 106-108.

32 H o6-10, minutes of 1st commission meeting, 17 May 1969, 9, 10; ibid., Letter from Prof. A. Gigon to the members of the commission, 11 July 1969. A federal commission for nuclear energy was installed in $195^{8}$ and a federal commission for radiation protection initiated in 1966; see Eduard Müller-Schärer, Ein Beitrag zur Geschichte des Strahlenschutzes in der Schweiz (Bern, 1989), www.bag.admin.ch/dam/bag/de/dokumente/str/kommissionstrahlenschutz/kontakt-geschichte/geschichte-strahlenschutz-ch-1989.pdf.download.pdf/ geschichte-strahlenschutz-ch-1989.pdf, accessed 30 August 2021.

33 See Beat Bächi, "Grenzwertpolitik am Arbeitsplatz. Der Arbeiterkörper im 'MenschMaschine-Umwelt-System’ zwischen individueller Prävention und Sterberate der Population (1955-1980)," in Kontrollierte Arbeit - disziplinierte Körper? Zur Sozial- und Kulturgeschichte der Industriearbeit im 19. und 20. Jahrhundert, ed. Lars Bluma and Karsten Uhl (Bielefeld, 2012), 219-247.

34 Niklas Luhmann, "Risiko und Gefahr," in Soziologische Aufklärung 5. Konstruktivistische Perspektiven, ed. Niklas Luhmann (Opladen, 1990), 131-169. 
society; 35 applied to our case, it becomes clear that the boundaries between the systems of medicine, science, and politics had increasingly become porous, leading to growing mutual recourse between them. ${ }^{36}$ Biomedical ethics came to be situated at the intersection of those areas.

In the discussions, the model of dealing with technology risks, such as radiation protection, initially formed an important point of reference. But what the commission was dealing with had a different shape: while technology risks could be assessed with numbers, e.g., with the instrument of "threshold values", ethical risks seemed beyond a numerical or sociological reach. ${ }^{37}$ They had to be governed by values. ${ }^{38}$

There were risks emanating from human trials per se, such as side effects or harms to patients, but also more diffuse dangers or risks, such as disregard for personal rights, the question of consent, or the danger that society might develop distrust of the medical profession as a consequence of unethically conducted human experimentation. While the commission agreed that human research was necessary, its limits were controversial. One participant noted that the limits lay primarily with the person of the researcher, arguing that they are found in "the intention, in the attitude, but not in the risk". A psychiatrist argued that risk had to be balanced against therapeutic benefit; a line of thinking that later became accepted for human trials, where individual interests are weighed against medical progress and the public interest. ${ }^{39}$

The commission initially tried to distinguish between "dangerous experiments", such as metabolic studies with radioactively marked substances, where the long-term "risk" seemed incalculable, and "harmless investigations". ${ }^{40}$ The latter pertained to daily bedside practice, such as the measuring

35 Ulrich Beck, Risikogesellschaft. Auf dem Weg in eine andere Moderne (Frankfurt am Main, 1986).

36 On mutual recourse, see Sybilla Nikolow and Arne Schirrmacher, eds., Wissenschaft und Öffentlichkeit als Ressourcen füreinander. Studien zur Wissenschaftsgeschichte im 20. Jahrhundert (Frankfurt am Main, 2007).

37 On threshold values, see Bächi, "Grenzwertpolitik am Arbeitsplatz"; on governing by numbers, see Peter Miller, "Governing by Numbers: Why Calculative Practices Matter," Social Research, 68 (2001), 379-396 and Theodore Porter, Trust in Numbers: The Pursuit of Objectivity in Science and Public Life (Princeton, NJ, 1995).

38 On governing by values, see our research project at www.img.unibe.ch/forschung/medizin_ und_bioethik_in_der_schweiz/index_ger.html, accessed 30 August 2021.

39 H o6-10, minutes of the 1st commission meeting, 17 May 1969, 10.

40 Ibid., 9. For the connection between bioethics and the atomic age, see Joachim Radkau, "Hiroshima und Asilomar. Die Inszenierung des Diskurses über die Gentechnik vor dem Hintergrund der Kernenergie-Kontroverse," Geschichte und Gesellschaft, 14 (1988): 329-363, 331. 
and comparing of blood pressure. Some opposed, stating that there was no medical intervention without risk: "Is there such a thing as a risk-free puncture?", asked one member, rhetorically. ${ }^{41}$ Risk, in this view, pertained not only to dangerous materials and thus to the hard sciences, but was intrinsically linked with medicine.

The same ambivalence applied to medical progress. For some, it was part of their professional ethos to provide the best and latest treatment to their patients, and they thus generally endorsed research. For others, medical research had potentially far-reaching side effects. In the first session, a neurosurgeon gave a general introduction in which he pointed out the ambivalence inherent in medical progress: in his view, while advances in microbiological research have helped to combat infant mortality, they inadvertently led to an "enormous population growth" and the problem of ageing societies. In the process, he said, man has inevitably become an "experimental object" and thus an instrument for generating new knowledge. ${ }^{42}$

Fittingly for the risk discourse, the dimension of the future also played a central role in the discussions. Whether or not a clinical trial was justified depended critically on how the results could be used in the future, one member argued..$^{43}$ Disregarding a person's rights and putting the public interest first seemed justified, at least to some discussants, if it promised "significant insight" in the future in terms of "medical progress", even to the point of hiding a trial from a patient. ${ }^{44}$ However, doubts arose as to who would be able to judge what exactly the future benefits and public interest were. Some declared themselves "positively biased" and unable to speak for society. One participant, invoking history to support his argument, referred to the Nazi experiments on humans, which were also conducted in the name of "public interest". 45

In addition to negotiating risks, dangers and responsibilities, ambivalence also arose in the commission as to what was the appropriate wording for this kind of research. Perhaps in keeping with a general caution, the terms "trial" and "experiment" were underlined with a wavy line in the first draft of the protocol, possibly signaling that they were still up for discussion. ${ }^{46}$

41 H o6-10, minutes of 1st commission meeting, 17 May 1969, 9.

42 Ibid., 2 f.

43 Ibid., 10.

44 Ibid.

45 Ibid. On the uses of historical arguments, see Silke Schicktanz, Susanne Michl and Heiko Stoff, "Bioethics and the argumentative legacy of atrocities in medical history: Reflections on a complex relationship," Bioethics, Special Issue: Legacy of the Holocaust (2021), 1-9.

46 H o6-10, minutes of 1st commission meeting, 17 May 1969. 
Two contrasting foils served to frame these conceptual struggles: the inhumane Nazi experiments and animal trials. The term "human trials" was to be avoided at all costs, members agreed, even though that was crucially what the guidelines were about. ${ }^{47}$ The commission grappled for a long time with what to call the guidelines, finally agreeing on the softer term Forschungsuntersuchungen, i.e., research investigations, which sounded more neutral and did not evoke the associations that the German word for trial had in members' ears. ${ }^{48} \mathrm{~A}$ single participant criticized the solution as "trivializing", especially since it could also just mean "examination". For the others, "trial" and "experiment" sounded too reminiscent of the Nazi era, or blurred the line between species, making humans into "trial rabbits" (guinea pigs). After all, human bodies could not be experimented on in the same way as animal bodies: "In animal trials", it was stated, "the animal is sacrificed; this is out of the question for humans".49

Given the combination of professions in the commission, the ambiguity about the experimental and biomedical turn in medicine is not surprising. Ilana Löwy has described how modern medicine has increasingly relied on technologies, instruments, and drugs, making it more difficult to distinguish between medicine, science and industry. ${ }^{50}$ Since the therapeutic revolution, the clinic has become a "unique site of knowledge production", 51 and the advent of clinical trials has added a statistical and experimental logic to the clinical gaze. As Löwy argues, here a "statistical body" took the place of the concrete suffering body of the patient. Impersonal, randomized and blind evaluations increasingly challenged or even replaced the clinical judgment of doctors, leading to competition between different professional approaches from inside the clinic and outside. ${ }^{52}$

It was these irresolvable dilemmas between patients' interest, scientific progress, and public health, together with the above-mentioned concerns about risk and dangers, that finally led members to recommend the independent establishment of "advisory bodies" for human trials. ${ }^{53}$ Such bodies, the consensus went, should be "consultative or advisory", but still "willing to take over

\footnotetext{
47 Ibid., minutes of 3rd commission meeting, 13 December 1969, 4.

48 "Versuchskaninchen", the German word for Guinea pig, literally translates as 'trial rabbit'.

49 H o6-1o, minutes of and commission meeting, 27 September 1969, 2f.

50 Ilana Löwy, “Historiography of Biomedicine: 'Bio,' 'Medicine,' and In Between," Isis, 102 (March 2011): 116-122, 116.

51 Ibid.

52 Ilana Löwy, "The Experimental Body," in Medicine in the Twentieth Century, ed. Roger Cooter and John Pickstone (Amsterdam, 2000): 435-450, 443 .

53 B o1-6, minutes of board meeting, 27 May 1969, 18.
} 
responsibility". ${ }^{54}$ In the final form of the guidelines, all references to "control" were replaced with the word "review". Members agreed that this should not be mandatory, but only upon request. ${ }^{55}$ A welcome side effect of such panels was also the distribution of risk coverage and potential financial and legal liability. ${ }^{56}$

Nevertheless, there were concerns at the Academy about limiting the freedom of research and the liberty of physicians, about curtailing the growth of the pharmaceutical industry, and about creating the impression of a top-down, centralized governance, which contradicted the Swiss federalist system of health politics. These concerns led to a rather soft and tentative wording in the final version of the guidelines, with regard to establishing ethics committees: "It is recommended that advisory bodies be established to which the medical and ethical aspects of a proposed research investigation can be submitted", the published paragraph read. ${ }^{57}$

Despite this restraint, the guidelines met with some protest. The Society of Urology wrote that the guidelines were uncalled for and would literally make future research impossible, calling them a "legal fence and regimentation". 58 Indeed, the commission had shared this concern, but nevertheless wanted to occupy and shape an increasingly contentious field, which otherwise risked being legislated.

Although the Academy had drawn up a first code of conduct for research on humans (1970) and recommended the independent formation of "advisory bodies", its efforts had not resonated much, as was discovered years later. In 1975, the SAMS sent out a letter to the five faculties and to 44 major hospitals in Switzerland. "Given the fact that the problem could become subject of a public discussion", the Academy wanted to know whether there were any committees monitoring human research in the country, and if so, how they operated. ${ }^{59}$

\footnotetext{
54 Ibid., 12.

55 H o6-10, minutes of 3rd commission meeting, 13 December 1969, $8 f$.

56 Ibid.

57 Schweizerische Akademie der Medizinischen Wissenschaften, Richtlinien für Forschungsuntersuchungen am Menschen (Basel, 1970), 4.

$5^{8} \quad \mathrm{H}$ o6-9, registered letter from the Swiss Society of Urology to the board of the sams, 20 October 1971.

59 H 17-4, Letter from sams to the medical faculties and hospitals, 14 February 1975.
} 
It also asked whether the local solution was satisfactory. The response, however, was "disappointing", bringing only "meager results". ${ }^{60}$ Months later, only 13 answers had arrived, painting an extremely heterogeneous picture. ${ }^{61}$ Some of the positive replies stemmed from former members of the commission working on the guidelines, while one clinic took the inquiry as an incentive to form a new committee. ${ }^{62}$ Two mid-sized hospitals reported that they had neither committee nor guidelines, but were willing to distribute the Academy guidelines among their chief doctors; at least four hospitals replied that they did not have and did not wish to have such committees, with all responsibility lying in the "competence of the chief physician". ${ }^{63}$ The Academy concluded that the guidelines were generally not known well enough, and that in many places "the importance and possible consequences of studies with humans are underestimated". ${ }^{64}$

Initial pressure to assess the situation had come from the media. In 1974, a "British-American film" on the subject of human experimentation was shown on Swiss television. In the accompanying interview, a professor of internal medicine and member of the commission preparing the guidelines was asked whether the "advisory bodies" recommended in 1970 by the Academy existed at all in Switzerland: "I was glad to be able to point out that such a committee exists and functions well at the Children's Hospital in Zurich" and to point to another one in Bern, the professor wrote to the Academy with relief. Subsequent inquiries among colleagues, however, led him to suspect that there were hardly any comparable bodies elsewhere in the country. Although many things spoke against such bodies in his eyes - "exaggerated bureaucracy", "inconvenience" - he argued in their favor, above all, in order "to avoid possible government interference, which would be of great disadvantage" and could hinder research, and to "at least bear the moral responsibility in case of challenges". ${ }^{65}$ Added to this also came pressure from outside: by 1975, the wHo had pointed out the desirability of "Institutional Review Boards" and the Second Declaration of the World Medical Association in Tokyo prescribed independent committees for trials on humans as well. ${ }^{66}$

60 H 17-4, First Ethics Survey, summary by Prof. R. Wenner, 17 October 1975; B o1-8, minutes of board meeting, 3 March 1977 .

61 B o1-8, minutes of board meeting, 3 April 1975 .

62 H 17-4, First Ethics Survey, list with handwritten comments, 18 September 1975.

63 Ibid., summary by Prof. R. Wenner, 17 October 1975.

64 Ibid.

65 Ibid., Letter from Prof. A. Labhart to the President of SAMS, 24 February 1974.

66 Historical discussion in B o1-8, minutes of board meeting, 18 October 1979, 2. 
Puzzled by the non-reaction of institutions in the country, the Academy decided to wait and lobby medical deans and hospital heads through personal connections. ${ }^{67}$ By the end of 1975, a coordinated promotional strategy was embraced: the guidelines were sent out to all chief physicians and republished in the Swiss Medical Journal, with the Academy pointing out that although "not new", they were extremely relevant. ${ }^{68}$ The missing RECs led some at the Academy to doubt the strategy of issuing guidelines and to consider instead installing an "appropriate oversight body", not least due to fear of litigation. ${ }^{69}$

However, there is a fundamental difference in the logic of committee work and of codes of conduct, as Hedgecoe and Stark have argued: while the ethical code-approach aims to discipline a minority of investigators - only the "rare and egregious abuser" -, REC s are a more routine way of supervising each research project. ${ }^{70}$ The latter are not based on the model of exception, but on generalized scrutiny. Furthermore, guidelines belong to the realm of paperwork. Tables, questionnaires, reports and dossiers have become crucial epistemic and administrative tools in modern societies for the planning, survey, judgement and examination, and ultimately the production of authority and objectivity. ${ }^{71}$ As tools, guidelines are thus categorically different from committee work. Maybe unwittingly, the Academy had pursued two competing logics at once: routinized committee work and the paper tool of guidelines.

Throughout the 1970s, the Academy occasionally received requests from physicians, cantonal authorities or hospitals to decide on ethical questions or to form a consultative body performing supervisory tasks. It declined all of them, partly because health care in Switzerland was organized on a cantonal basis. $^{72}$ The tide turned in 1977: in an apparent reversal of course, the Academy decided to form an ethics committee of its own without clearly defining its form. In the end it turned out to become more of a policy body, setting rules and offering guidance, but in the beginning, it was thought to also function more as a hands-on committee, regularly reviewing issues arising from practice in hospitals and research. The new "central medical-ethical committee"

67 B o1-8, minutes of board meeting, 3 April 1975, 3 f.

68 H o6-9, Schweizerische Ärztezeitung, 28 April 1976; B o1-8, minutes of board meeting, 23 October 1975, 1of.

69 Ibid. Fear of litigation had been a crucial driver for IR B s in the U.S.; see Stark, Behind Closed Doors, 156 .

70 Hedgecoe, "A Form of Practical Machinery," 333 with reference to Stark.

71 See Peter Becker and William Clarke, "Introduction," in Little Tools of Knowledge: Historical Essays on Academic and Bureaucratic Practices, ed. Peter Becker and William Clarke (Ann Arbor, MI, 2001), 1-33.

72 H 17-5, typescript, 5 November 1976; B o1-7, minutes of board meeting, 25 February 1971, 4. 
was instituted in 1979, but started working in a "pre-consulting" form immediately in 1977. It later evolved into the most important body of the Academy, responsible, among other things, for issuing a growing number of guidelines, consulting for individual physicians, hospitals, researchers and policymakers and it generally attained an expert status in biomedical ethics. In the beginning, the format was fluctuating, reactive and tentative, and its mandate was to discuss the "problems of medical ethics". A comprehensive codex of ethics, such as the one drawn up in France, was to be avoided come what may. "In Switzerland", it was stated, "any hint of dirigisme as found in France should be avoided at all costs". ${ }^{3}$

A wide range of other ethical issues quickly joined the concern about research ethics. Since the body was considered "advisory" rather than strictly controlling, it made sense that it would fulfill consulting roles on multiple issues, such as end-of-life-decisions, sterilization, artificial insemination or forcible treatment in psychiatry. A sharp distinction between REC s and ethics committees was only introduced much later, in 1992, with the establishment of a supra-regional ethics committee responsible for multicenter clinical trials. ${ }^{74}$

So how can this change of course - from a hand-off approach to the proactive forming of a centralized committee - be explained? Research funding played a decisive role here, possibly marking a growing mutual recourse between science and politics. ${ }^{75}$ In the summer of 1977 , the main funding body for research, the Swiss National Science Foundation, sent out a letter to all medical deans with a copy to the Academy inquiring about the "existence of ethical committees". It found their number insufficient and announced that, in the future, all funding applications involving studies on humans had to include a statement from an ethics committee. ${ }^{76}$ This effectively changed the rules of the game. In addition, some Academy members, particularly from the pharmaceutical industry, had already repeatedly drawn attention to the U.S. and the United Kingdom, and pointed out that Switzerland was lagging behind in an international trend: elsewhere, "practically every hospital" had such a committee, and in their view it was time for the Academy to at least take up a coordinating and harmonizing role in this matter. ${ }^{77}$ Similar to the standardization

73 B o1-8, minutes of board meeting, 6 October 1977, 13 .

74 Hi3-11, minutes of zE K-meeting, 20 November 1992, 3f.

75 See Nikolow and Schirrmacher, Wissenschaft und Öffentlichkeit als Ressourcen; see also Hedgecoe, "A Form of Practical Machinery," 335.

76 B 13-10, minutes of senate meeting, 27 October 1977, 9.

77 B o1-8, minutes of board meeting, 3 March 1977, 9. 
of clinical trials, the pharmaceutical industry was a driving force behind these developments, as it had a vested interest in global market access. ${ }^{78}$

The landscape was also shifting for the Academy as an organization: it sat increasingly uncomfortably between physicians, the pharmaceutical industry, and politics. In the late 1970s, it received more and more requests from federal authorities for statements on ethical issues, and initially did not know how to respond to them, especially since, as one member noted, "[...] so far the Academy is still supported by the donors and they might not appreciate it if we fulfill more and more tasks for the federal government with their money". ${ }^{79}$ Representatives of the industry, on the other hand, criticized the fact that the Academy activities were "almost exclusively in the service of the medical profession". ${ }^{80}$

Unlike in other countries, the Academy still was a private foundation and, as members were reminded, was financed "to about $90 \%$ by the chemical industry". ${ }^{81}$ In 1976 and 1977, several letters arrived from Ciba-Geigy and Roche, with the former announcing that "in view of the recession" it would be forced to reduce its contributions substantially (by "up to $20-25 \%$ "), and with both companies cutting their donations by 10,250 Swiss Francs the following year. ${ }^{82}$ Among other things, these announcements forced the Academy to rethink its structure and to consider working more closely with policymakers - and, in view of a planned federal research law, to attempt to be recognized as an official academy by the state and thus to become eligible for government subsidies. ${ }^{83}$ These factors contributed to the Academy transforming itself into a more active player in the field of biomedical ethics, and to decide to address ethics not only through codes but also through a central committee.

78 See Marietta Meier, Mario König and Magaly Tornay, Testfall Münsterlingen. Klinische Versuche in der Psychiatrie, 1940-1980 (Zürich, 2019), chapter 4; Harry Marks, The Progress of Experiment: Science and Therapeutic Reform in the United States, 1900-1990 (New York, 1997); Nancy Campbell and Laura Stark, "Making up 'Vulnerable' People: Human Subjects and the Subjective Experience of Medical Experiment," Social History of Medicine, 28 (2015): $825-848$.

79 B o1-8, minutes of board meeting, 29 March 1979, 9; G12-6, memo of the meeting on 11 January 1979 with Prof. Hausheer, Vice-director of the Federal Office for Justice, 3 f.

$80 \quad$ B 13-10, minutes of senate meeting, 27 October 1977, 7.

81 B o1-8, minutes of board meeting, 18 March 1976, 9 .

82 Ibid.; B 13-10, minutes of senate meeting, 27 October 1977, 7; B o1-8, minutes of board meeting, 6 October 1977,8 .

83 Negotiations with the government were initiated on 21 December 1976 and were, ultimately, successful. After the voters first rejected the federal research act in May 1978, a new version was accepted in October 1983. The SAMs was able to ask for bridging subsidies ad interim. B13-10, minutes of senate meeting, 25 March 1977, 4; ibid., minutes of senate meeting, 14 November 1979, 6 . 
Still, it was crucial for all involved parties that the central committee was independent of any state structure. Even though the European Council recommended that such bodies be subject to state legislation, the Academy reasoned, "control at the national level can just as well be carried out by non-state actors". Furthermore, it re-emphasized that "in Switzerland, pharmaceutical companies take ethical considerations into account at all stages of clinical trials". ${ }^{84}$

In the Swiss drug regulatory agency also, there was approval of the fact that "government regulation" had been avoided so far, "but this will only be possible in the future if the problems of medical ethics are tackled at another level and solved as far as possible". ${ }^{85}$ For a representative of the pharmaceutical industry, who like the regulatory agency was involved in the central-committee discussions from the very beginning, the committee could also serve to "evaluate whether trials are tolerated by society". 86

What was changing, though, was the desired composition of local committees: the Academy wrote to the hospitals that the local committees should not exclusively consist of physicians, but include both genders "as well as nurses, lawyers, sociologists etc.", dropping the mention of sociologists in a later letter. ${ }^{87}$ For its own central committee, it invited a French-speaking female nurse and a female physician. ${ }^{88}$

By the 1980s, the committee had embraced a twofold strategy: to consolidate itself in the heart of the Academy and to further encourage local ethics committees. ${ }^{89}$ Both should not limit themselves to research ethics, but treat multiple ethical issues. By now, these "genetic-psychological-social problems", as one member called it, needed to be addressed on multiple levels: nationally, by the centralized committee; regionally, by the faculties and hospitals; and in smaller hospitals, on a case-by-case basis, through discussions between physicians, with the possibility of appeal to the Academy. ${ }^{90}$

84 H 17-4, draft for guidelines on medical ethics, 1 February 1980, gf.

85 H 18-9, letter from Dr. P. Fischer, head of IKs, to O. Gsell, SAMW, 19 February 1980.

$86 \mathrm{H} 18-12$, minutes of the meeting of the subcommittee on I Ks, Interpharma, transplantation, 17 March 1979, 2; ibid., minutes of the meeting of the subcommittee on ethical questions, 2o September 1979, if.

87 H 17-4, Letter to chief physicians from Prof. Mach, SAMS, 25 July 1979.

88 The inclusion of women was decided by the senate. G 12-6, minutes of meeting of the pre-consulting committee, 12 May 1979, 4.

89 It continued its survey-strategy bringing substantially better results only in 1988; see M. Ummel, "Les commissions d'éthique en Suisse. Développements factuels et questions critiques," Cahiers médico-sociaux, 39 (1995), 81-9o; O. Gsell, "Medizinisch-ethische Kommissionen der Krankenhäuser in der Schweiz," Schweizerische Ärztezeitung, 27 (1979), 1345-1350.

$90 \mathrm{G}$ 12-6, minutes of pre-consulting meeting, 1 February 1979. 
However, although the central committee had been founded precisely out of concern about the lack of REC s, it ultimately did not end up reviewing many research proposals. Rather, its core tasks evolved to constitute the working out of guidelines, norms and advice, fluctuating between a normative and a consulting role. The initial idea that it would become the national body for appeals and for coordinating research ethics committees, as well as filling the void in places without a local committee, ultimately failed - not least because the SAMS itself was reluctant to take on such an active role. It could, however, examine research protocols in hospitals without an REC or upon request, but without appeal authority.

Attempts to take on a more active role and to codify biomedical ethics also faced resistance from the outside. The physicians' association of Geneva, for example, objected on grounds of cantonal autonomy in professional matters that the "central medical-ethical committee" would be endowed with such powers. ${ }^{91}$ The Swiss Medical Association, in a sharply-worded letter, called the plans of the central committee an attempt to penetrate too deeply into the field of practical physicians' ethics. It also criticized attempts to install a "supreme court appeal authority", which went far "beyond the framework set for the sAMs". It also found the attempt to codify general medical ethics "extremely questionable": "Church history teaches us", the letter concluded, "that not even religious authorities have succeeded in formulating ethical principles accepted by a larger circle without contradiction". ${ }^{2}$

The drive to regulate research ethics and to solve the case of the missing REC s had effectively reshaped the Academy and had placed it, at times, at odds with other actors. Nevertheless, it became a central player in the emerging field of biomedical ethics, embodying more and more topics and forming countless sub-commissions and working groups to tackle them. Even though the handling of research ethics was still extremely heterogeneous and without a clear legal basis, the Academy had set in motion a process to address these issues, which seemed to reproduce itself over and over, but managed to secure the freedom of research and the liberty of physicians. ${ }^{93}$

91 H 18-10, Letter from the physicians' association of Geneva to the presidents of sAms, 6 February 1980.

$92 \mathrm{H} 18-9$, Letter from the central board of FMH to the presidents of SAMS and ZEK, 7 March 1980.

93 On this, see Luhmann's notion of "legitimation by procedure": Niklas Luhmann, Legitimation durch Verfahren (Frankfurt am Main, 1969). 
Even though the Academy had ensured that its paperwork also reached peripheral areas and smaller clinics, a gap remained with sites of practice. This gap is telling, since the guidelines and policies of the sAMs had a distinctly provisional character: they were often revised, reformulated, or adapted, and crucially did not prescribe any implementation or course of action. The point was precisely to maintain a certain openness, to find a form that was at once fixed and unfixed, in order to prevent politics from taking over the field.

Take, for example, the Münsterlingen Psychiatric Clinic, one of the most prolific sites for clinical trials in psychiatry in the second half of the twentieth century. Even though the guidelines on "Research Investigations in Humans" lay in duplicate in the archives of its director, Roland Kuhn, they bear no marks - creases or underlinings of the kind he usually applied to his papers - indicating that they had not spent much time outside a drawer and had not been read closely. The Academy letter inquiring about ethics committees also reached Kuhn, but a response is missing in the archives. ${ }^{94}$

Its guidelines on research ethics, as the Academy had begun to suspect in the mid 1970s, had led a shadowy existence not only with Kuhn but in other clinics as well. Medical practice and ethical codification did not seem to connect in a soap-and-dirt kind of way. Even though Kuhn was one of the main protagonists of clinical trials in Swiss psychiatry, testing a large number of substances for the Basel firms without consent, protocols or approval by committees, he remained untouched by the codification efforts. Ethical considerations were almost entirely absent from his thinking and modus operandi. It took until the end of the 1980 os before consent forms were signed by patients for the first time and before trials were carried out according to a protocol explicitly referring to the "ethical requirements" of the Declaration of Helsinki - albeit on the initiative of the company Ciba-Geigy, not the clinic or the authorities. ${ }^{95}$

Thus, the disconnect between research ethics norms and practice, which the Academy had identified in its first survey, actually lasted much longer than suspected. This may be especially true for places like Münsterlingen - a rural psychiatric clinic on the periphery in a canton without university -, where one suspects less supervision than in university clinics.

But it is precisely the canton of Thurgau, where Münsterlingen is located, that became a pioneer in setting up an REC. In 1987, it installed the first cantonal ethics committee in the country by law and charged it with reviewing

94 For this episode, see Meier et al., Testfall Münsterlingen, 2oof.

95 Ibid. 25o. 
protocols for human research. In contrast to the revised version of the Academy guidelines from 1981, which stipulated a duty only to consult, it made approval by the ethics committee mandatory by law for any human trial. ${ }^{96}$ Several drivers were behind this, one of which was a scandal that broke in 1986 and triggered a debate on patients' rights, spurred by growing criticism and scrutiny at the political level, especially from representatives of the left-wing parties. ${ }^{97}$ For decades, a local doctor and cantonal health official had conducted clinical trials in a home with residents with impaired power of judgment, without consent or proper protocols, sometimes inventing test results and keeping the compensation for himself. A whistleblower had spoken out, which first triggered a disciplinary inquiry and later grew into a media scandal. By 1987, mounting pressure had led to an expanded formulation of patients' rights in the new law, which coincidentally had been in the making right when the scandal broke. ${ }^{98}$ The case even found its way into The Lancet. Under the telling headline "Where are the cantonal ethics committees?", it expressed shock at the lack of control over clinical trials in Switzerland and noted that the existing central medical-ethical committee of the Academy had not been consulted. It further demanded that the guidelines on "Research Investigations in Humans" were declared binding. ${ }^{99}$ Nevertheless, the narrative of a scandal-driven change fails to fully explain the case of the Thurgau REC. The scandal increased pressure to turn the tide in a political process that was already underway, involving an increasingly wide range of actors; but more importantly, Pro Mente Sana, an advocacy group for the rights of psychiatric patients, began actively lobbying the regulation of patients' rights in drugs trials in all Swiss cantons. ${ }^{100}$

Ethics committees and RECs, however, remained an elusive and moving target up until the 1990s, as did knowledge of their existence, composition and modes of functioning. The landscape was heterogeneous, with various formats of ethical bodies coexisting, evolving and constantly modifying in Switzerland. ${ }^{101}$ It was not until 1992 that the Academy created a supra-regional ethics committee responsible for multicenter studies and for filling the gap

96 Christoph Jenni, Forschungskontrolle durch Ethikkommissionen aus verwaltungsrechtlicher Sicht. Geschichte, Aufgaben, Verfahren (Zürich-St. Gallen, 2010), 40-42; Niklaus Müller, "Das Disziplinarverfahren gegen den Thurgauer Kantonsarzt Hans Schenker im Jahr 1986 und seine Folgen" (bachelor thesis, History Institute, University of Zurich, 2018).

97 Meier et al., Testfall Münsterlingen, 255-257.

98 Müller, "Disziplinarverfahren gegen den Thurgauer Kantonsarzt Hans Schenker," 31-35.

99 Anon., "Where are the cantonal ethics committees?" The Lancet, 8529 (14 February 1987), 378.

100 FM H-Archive, 00232967, Letter Pro Mente Sana to Swiss Medical Association, 9 December 1986; Neue Zürcher Zeitung (14 January 1987), 34. 
in places without REC s. A more extensive legal basis for research ethics committees was not established until the Intercantonal Ordinance on Medicinal Products in Clinical Trials in 1993 and finally the Federal Law on Therapeutic Products in 2002.

The analysis of the prehistory of RECs in Switzerland shows that the paperwork of the SAMS deliberately avoided prescribing any implementation, allowing for considerable scope for interpretation. Research ethics brought together a number of historical strands: scientific experiment on humans expanded beyond the traditional doctor-patient relationship and introduced new categories, such as future risks and benefits, individual rights and the dilemma of responsibility. While recognizing that, at times, such questions might require more diverse expertise, Academy members first wanted to keep these matters away from any outside interference, all the while actively occupying the field.

In the end, issues around human experimentation opened the door for biomedical ethics more generally into the realm of the Academy, not least because it felt compelled to establish its own central medical-ethical committee. Eventually, it was also prompted to include more actors from 'outside', abandoning its initial insider approach. Biomedical ethics, it turned out, was here to stay, and it concerned not only the medical profession, but larger society.

Finally, the role of ethics in this story was not that of 'soap' directly removing 'dirt', i.e., solving a particular problem. Rather, it set in motion a further ethicization. What emerged along the way was not trust (or doubt) quite yet, but primarily a process that spawned other processes - inquiries, guidelines, or working groups -, with the goal of facilitating research and avoiding legal and political scrutiny. Ultimately, ethics might be a conversation that perpetuates itself, along with the institutional practices that accompany it. This conversation seeks to build trust by bringing more actors into the conversation, but it also reduces social complexity by translating it into the language of biomedical ethics. 